\title{
SEASONAL VARIATION OF EDAPHIC FEATURES OF MADHUPUR SAL FOREST, BANGLADESH
}

\author{
Ahmed Emdadul Hoque, A.K.M. Nazrul-Islam and S.M. Imamul Huq \\ Ecology Laboratory \\ Department of Botany \\ University of Dhaka, Dhaka, Bangladesh
}

\begin{abstract}
Seven stands were selected in different areas of the Madhupur Sal (Shorea robusta) forest to study the seasonal varation of available nutrients in soils. Soil samples were collected after every two months at two depths (top soil $0-10 \mathrm{~cm}$ and $10-20 \mathrm{~cm}$ ) and their physicochemical properties were determined. The percentage of soil moisture was found to vary in different stands and $\mathrm{pH}$ values of soil ranged from 4.60 to 6.28 . Seasonal fluctuation of elelctrical conductivity was observed. An increasing trend of sodium accumulation was found in both top and sub-soil layers at all the stands. The concentration of potassium also showed a decreasing tendency in both layers. The exchangeable calcium and magnesium contents did not show significant $(\mathrm{pH} 0.05)$ seasonal variation. The high values of manganese and iron were confined to top soil and values decreased down the profile.
\end{abstract}

Key words: Shorea robusta, soil, physico-chemical characteristics, seasonal variation.

\section{INTRODUCTION}

Soil, water and air are integral parts of our natural environment. The total environment has usually been considered only in attempting to exclude limiting factors, so that optimum responses to soil management treatments could be determined. Scientists have paid much attention to potential impacts of these management practices on water and air quality.

Man made threats to soil quality include accelerated erosion, excessive or improper cultivation, inadequate recycling of nutrients, accumulation of salinity, acidic deposition and additions of toxic materials in all manner of wasted as well as in agricultural chemicals. These factors will not be eliminated until proper remedial measures become part of everyday field practice.

Soils developed on recent alluvium depend for their properties partly on the texture and origin of their parent material and partly on drainage conditions. The alluvia of most rivers crossing Bangladesh are predominantly silty, but more sandy materials usually occur near active and abandoned river channels, and clays often occupy basin sites; organic matter has sometimes accumulated in basin sites too. The relative extent of sandy, silty and clayey deposits varies among the major river systems.

The soil of the Madhupur jungle is surprisingly heterogeneous. This heterogeneity is partly 
attributable to original differences in the nature of the Pleistocene deposits, but differences in drainage resulting from different amounts and perhaps periods of uplift and dissection appear also to have had an important influence. Soil type influences plant growth and Erica tetralix showed very poor growth on humus and peat soil as compared with mineral soil (Bannister 1964). There is evidence that calcium and magnesium in soils of Sal forest are usually returned to it by litter fall (Puri 1952).

It should be mentioned that during monsoon season (May to August) the forest is flooded periodically (6-10 days) and dried up. The chemistry of submerged soils and the changes due to drying and rewetting affect the growth of plants. The chemical changes that occur in different soil types due to drying and rewetting may help to explain the adaptation and distribution of plants (Pearsall 1938, Pearsall and Mortimer 1939) and also the availability of $\mathrm{Mn}$ and Fe in soils (NazrulIslam 1989). The availability of these two ions is dependent on aeration and organic matter and is more likely to occur at low $\mathrm{pH}$ values (Leeper 1947).

In the present paper physico-chemical characteristics of soils of Madhupur Sal (Shorea robusta) forest at different months of the year were studied at two depths from seven selected sites.

\section{MATERIALS AND METHODS}

Seven stands were selected in different areas of the Madhupur Sal forest to study the seasonal variation of available cations in soils. Soil samples were collected from the seven stands of Madhupur Sal forest with two months interval and their physico-chemical properties were determined. Four soil samples at two depths (top soil $0-10 \mathrm{~cm}$ and sub soil $10-20 \mathrm{~cm}$ ) were collected randomly from each stand.
Determination of soil moisture content: Ten gram of each of the fresh soils were weighed and dried at $100^{\circ} \mathrm{C}+5^{\circ} \mathrm{C}$ for $48 \mathrm{~h}$. The moisture content of soil was determined from the difference in weights of the wet soil, and the dry soil and the results were calculated on the basis of dry weight.

Determination of soil $\mathbf{p H}$ : For the determination of $\mathrm{pH}$ values, $20 \mathrm{~g}$ of fresh soil was taken in a clean and dry $100 \mathrm{ml}$ beaker. Then $50 \mathrm{ml}$ distilled water was added to the beaker and were thoroughly stirred with a glass rod for half an hour. $\mathrm{pH}$ of the suspension was determined with the help of an electrical digital $\mathrm{pH}$ meter (Gupta and Rorison 1974).

\section{Determination of soil electrical conductivity:} Electrical conductivity of the soil samples was determined within days after collection with the help of conductivity bridge (Gallen-Kamp). The soil was mixed with deionized water at a soil:water ratio of 1:5.

Physico-chemical characteristics of soils: Ten gram soil was weighed from each of the collected soil samples by digital electrical balance and was taken in $250 \mathrm{ml}$ plastic beakers. $100 \mathrm{ml}$ of $\mathrm{N}$ ammonium acetate adjusted to $\mathrm{pH} 7.0$ were added in three increments $(50+25+25 \mathrm{ml})$ and the beakers were shaken for $24 \mathrm{~h}$ at room temperature. The supernatant solution was filtered through Whatman No. 1 filter paper in a volumetric flask and then distilled water was added to the filtrate to make the volume $100 \mathrm{ml}$. Exchangeable sodium and potassium were analysed with flame photometer; calcium and magnesium were determined by atomic absorption spectrophotometer (Gupta and Rorison 1974).

Exchangeable manganese and iron were extracted with $0.1 \mathrm{~N} \mathrm{HCl}$ and analysed with atomic absorption spectrophotometer, Cation exchange capacity of soil was determined by $\mathrm{NH}_{4}$-saturation method followed by alkali distillation (Hessey 1971). 
Determination of soil organic matter: Two gram soil was weighed which has been passed through a $2 \mathrm{~mm}$ sieve and the soil was transferred to a $500 \mathrm{ml}$ clean dry conical flask. $10 \mathrm{ml}$ of $1 \mathrm{~N} \mathrm{~K}_{2} \mathrm{Cr}_{2} \mathrm{O}_{7}$ solution was added with the help of pipette and then $10 \mathrm{ml}$ conc. $\mathrm{H}_{2} \mathrm{~S}_{4}$ was added thoroughly and it was allowed to cool with occasional shaking for half an hour. An additional $10 \mathrm{ml}$ of $\mathrm{K}_{2} \mathrm{Cr}_{2} \mathrm{O}_{7}$ solution was added in cases where the colour turned green. After half an hour when the flask was cold, $150 \mathrm{ml}$ distilled water, $10 \mathrm{ml} \mathrm{H}_{3} \mathrm{PO}_{4}$ and $0.2 \mathrm{~g}$ of sodium fluoride were added; $3 \mathrm{ml}$ of diphenylamine indicator solution was added dropwise and the colour of the solution became deep violet and was cooled again. The excess of chromic acid left in the flask was titrated with the help of normal ferrous sulphate $\left(\mathrm{FeSO}_{4}\right)$ solution from a burette. At the end point the colour of the solution became deep bottle green. A blank experiment in the same way with all the reagents except soil was also done.

Calculation:

Organic C in soil $(\%)=\frac{(\mathrm{B}-\mathrm{T}) \times \mathrm{f} \times 0.003 \times 1.3 \times 100}{\mathrm{~W}}$

Where,

$\mathrm{B}=$ Amount in $\mathrm{ml}$ of $\mathrm{N} \mathrm{FeSO}_{4}$ solution required in blank experiment

$\mathrm{T}=$ Amount in $\mathrm{ml}$ of $\mathrm{N} \mathrm{FeSO}_{4}$ solution required in experiment with soil

$\mathrm{f}=$ Strength of $\mathrm{N} \mathrm{FeSO}_{4}$ solution (from blank experiment)

$\mathrm{W}=$ Weight of soil taken

It has been estimated that only about $77 \%$ carbon of the organic compounds in soil is oxidized by normal $\mathrm{K}_{2} \mathrm{Cr}_{2} \mathrm{O}_{7}$.

Organic matter $(\%)=\%$ of organic carbon $\times 1.72 *$

0.003 should be multiplied by 1.3 to get the percentage of total carbon present in the soil.

* = Since soil organic matter contains about 58\% of organic carbon.
Determination of cation exchange capacity (C.E.C.): Ten gram of soil sample was taken in a $250 \mathrm{ml}$ conical flask. $100 \mathrm{ml}$ of neutral, $1 \mathrm{~N}$ $\mathrm{NH}_{4} \mathrm{OAc}$ solution was added and the contents were shaken thoroughly and allowed to stand over night. The suspension was filtered through Whatman filter paper No. 44. The filtrate was collected in a $250 \mathrm{ml}$ volumetric flask and the volume was made upto the mark with $1 \mathrm{~N}$ ammonium acetate. The residue was washed five times with $10 \mathrm{ml}$ of absolute ethyl alcohol each time, till the residue was ammonium free. The soil was not allowed to dry and crack during washing and the filtrate was discarded. The soil materials were leached on the filter paper four times with neutral $1 \mathrm{~N} \mathrm{NaCl}$ solution in a flask of $250 \mathrm{ml}$ capacity and the volume was made up to the mark with $1 \mathrm{~N} \mathrm{NaCl}$ (pH 7.0) solution.

Alkali distillation: Ten $\mathrm{ml}$ of extract was distilled at a time with $10 \mathrm{ml}$ of $40 \%$ of $\mathrm{NaOH}$ using micro Kjeldahl's distillation apparatus with equal volume of $40 \% \mathrm{NaOH}$ and the distillate was collected in 25 $\mathrm{ml} \mathrm{H}_{3} \mathrm{BO}_{3}$ until the volume was $50 \mathrm{ml}$. The conical flask was removed; and washed the delivery outlet of the distillation apparatus with distilled water.

The distillate was titrated against $0.01 \mathrm{~N}$ $\mathrm{H}_{2} \mathrm{~S}_{4}$, until the end point became pink colour. A blank experiment was run simultaneously using all the chemicals except soil.

Calculation:

$\mathrm{N}$ in soil $(\%)=\frac{(\mathrm{T}-\mathrm{B}) \times \mathrm{f} \times 0.014 \times 100 \mathrm{ml} \text { extract } \times 100}{\mathrm{~W} \times \text { volume of extract used }}$

Where,

$\mathrm{T}=$ Amount in $\mathrm{ml}$ of $\mathrm{N} / 100 \mathrm{H}_{2} \mathrm{SO}_{4}$ required in titration of the experiment with soil

$\mathrm{B}=$ Amount in $\mathrm{ml}$ of $\mathrm{N} / 100 \mathrm{H}_{2} \mathrm{SO}_{4}$ required in titration of the blank experiment

$\mathrm{W}=$ Weight of the soil sample taken

$\mathrm{f}=$ Normality factor of $\mathrm{N} / 100 \mathrm{H}_{2} \mathrm{SO}_{4}$ 
Therefore, C.E.C., in me/100 g of soil $=\frac{X \times 1000}{14}$

Where, $\mathrm{X}=\%$ of $\mathrm{N}$ found in the above calculation.

\section{RESULTS AND DISCUSSION}

Physical and chemical properties of soil: To determine the nutrient status of forest soils, various physical and chemical properties such as, moisture content, $\mathrm{pH}$, electrical conductivity (Table 1), available potassium, calcium, magnesium, iron, manganese and sodium, (Table 1) contents were studied. All these properties have been known to be essential for the growth and development of forest plants.

Moisture content: The percentage of moisture content was found to vary from one stand to another in different seasons (Table 1). During the months of January-February the overall mean moisture content was $5.26 \%$ to $7.78 \%$ in top soil layer, and subsoil layer, respectively. In MarchApril, moisture content was $10.94 \%$ and $10.83 \%$; in May-June $23.82 \%$ and $22.11 \%$; in SeptemberOctober $20.87 \%$ and $20.60 \%$ in top and subsoil layers, respectively. In the months of NovemberDecember, soil moisture came down to $10.49 \%$ in top soil layer and $11.61 \%$ in subsoil layer.

An increasing trend of soil moisture was found among all stands in both top soil and subsoil layers from January to October but in November and December, soil moisture contents showed a decreasing trend. The highest percentage of moisture was noted in May and June. In general, the moisture percentage was high from June to September (monsoon season). Soil in the top soil layer had relatively less moisture content than sub soil layer.

pH values of the soil: $\mathrm{pH}$ values of the soil (Table 1) indicate that the soils are strongly acidic to moderately acidic and the values ranged from 4.6 to 6.28 . The $\mathrm{pH}$ values were a little bit lower in the subsoil than the top soil layer in all the stands. Seasonal variation of $\mathrm{pH}$ was observed in different stands.

Soil $\mathrm{pH}$ gives some measure of general level of fertility (Wilde 1954). Grubb (1963) noted low $\mathrm{pH}$ (4.2) with poor exchangeable potassium in Montane Forest soil where the vegetation was Dialyanthere otoba, Barnedesia trianae, Haleocarpus popayanensis. Eggeling (1947) also noted low $\mathrm{pH}$ (4.6 to 5.6) in the mixed forest of Uganda. Ovington and Madgwick (1957) have shown a positive correletion between $\mathrm{pH}$ of soils at different depths in woodlands and also those of the tree leaves and litter layers, despite the very wide range of ecological conditions.

Wide variation of soil properties from place to place makes it difficult to compare the results found in the acid soils (Baker and Clapham 1939).

Electrical conductivity: The values of conductivity showed strong variations in different stands (Table 1). Seasonal fluctuation of the electrical conductivity of soil was observed in different seasons. In the months of May-June, soil conductivity showed highest value (207.90 micromhos/cm) followed by January-February and March-April. Soil conductivity showed the lowest value in the months of September-October (34.65 micromhos/cm; Stand No. 5), November and December (40.04 micromhos/cm; Stand No. 7). It is possible that in the monsoon season salts were dissolved hence showed high value. Such a trend was reported in soils of mangrove forest of Bangladesh (Nazrul-Islam 1995).

The overall mean maximum value in top soil was 141.2 micromhos/cm in May-June and the minimum value was 50.95 micromhos/cm at 10-20 $\mathrm{cm}$ in September-October.

The exchangeable cations: Values for exchangeable $\mathrm{Na}$ and $\mathrm{K}$ contents are given in Table 1. Seasonal variation was observed in both 
$\mathrm{Na}$ and $\mathrm{K}$ contents. $\mathrm{Na}$ content of top soil was relatively greater than sub soil layer in all stands. The highest $\mathrm{Na}$ content was found in the month of November-December $1.02 \mathrm{me} / 100 \mathrm{~g}$ in top soil and the lowest $\mathrm{Na}$ content was observed in January-February, $0.15 \mathrm{me} / 100 \mathrm{~g}$ in sub soil layer.

This trend was not observed for K. Maximum value was obtained in January-February; 0.59 $\mathrm{me} / 100 \mathrm{~g}$ and the minimum value was $0.02 \mathrm{me} / 100$ $\mathrm{g}$ in September-October. The concentration of $\mathrm{K}$ also showed a decreasing tendency in both layers except in the soil collected in January-February.

The contents of calcium and magnesium are presented in the Table 1. The exchangeable calcium and magnesium contents did not show significant $(\mathrm{p}=0.05)$ seasonal variation. In general, calcium was higher than magnesium in both top and subsoil layers in all the stands. The overall mean value of exchangeable calcium was highest in September-October and lowest in NovemberDecember.

Data collected for the distribution of calcium at different depths in soil profiles under Sal community, in open grassy areas, and under different types of miscellaneous forest area by Puri (1952), which throw interesting light on the probable effect of climate on the development of soils in the area. In most types of soil, especially in the open or under miscellaneous species with little or no Sal or under clear felled or heavily felled patches in Sal forest upper layers (0-6") of the soil were almost always rich in exchangable calcium. In lower layers calcium showed an increasing trend under the effect of evaporation. On fire lines where vegetation is periodically felled and burnt, exchangeable calcium in upper layers was much higher than in lower layers. Under dense canopies of Sal with a thick under growth of Clerodendrum sp., Litsea and other sp., there was a faint trend in leaching with upper layers slightly poorer in exchangeable calcium than the lower layers.

Lutz and Chandler (1955) have noted that in temperate climate; calcium usually increases in lower horizon. Taylor et al. (1935) and Coile (1939) showed that deep rooted plants frequently build up the concentration of lime in the surface soil as a result of contribution made by leaf fall annually. In the present study the increase of calcium in first $10 \mathrm{~cm}$ may be due to decomposition of litter; subsequent decrease may be due to leaching; and final increase may be as a result of concentration of the element.

The exchangeable manganese and iron contents showed the seasonal fluctuation (Table 1). The high values of $\mathrm{Mn}$ and Fe were confined at top soil layer and values decreased down the profile. The average mean maximum value of $\mathrm{Mn}$ was $390.9 \mu \mathrm{g} / \mathrm{g}$ in top soil layer in May-June and minimum value was $101.56 \mu \mathrm{g} / \mathrm{g}$ in sub soil layer in January-February. An increasing trend of $\mathrm{Mn}$ was noted among all the stands in both top soil and subsoil layers from the months of JanuaryFebruary to June-July except October, November and December.

Water logging of soil showed high concentration of exchangeable $\mathrm{Mn}$ which causes injury and death to many species of crop plants and forest species (Grable 1966, Gill 1970, NazrulIslam and Rorison 1978, Nazrul-Islam et al. 1980). Iron and manganese availability in the soil is dependent on a number of factors which include the degree of acidity; aeration and the presence of organic matter (Rodrigo and Pollard 1962). Both elements exist in more than one valency state, the ions of higher valency being a less soluble than the lower forms. The total concentrations in the soil, therefore, will give no indication of the availability of either element to the plant. 


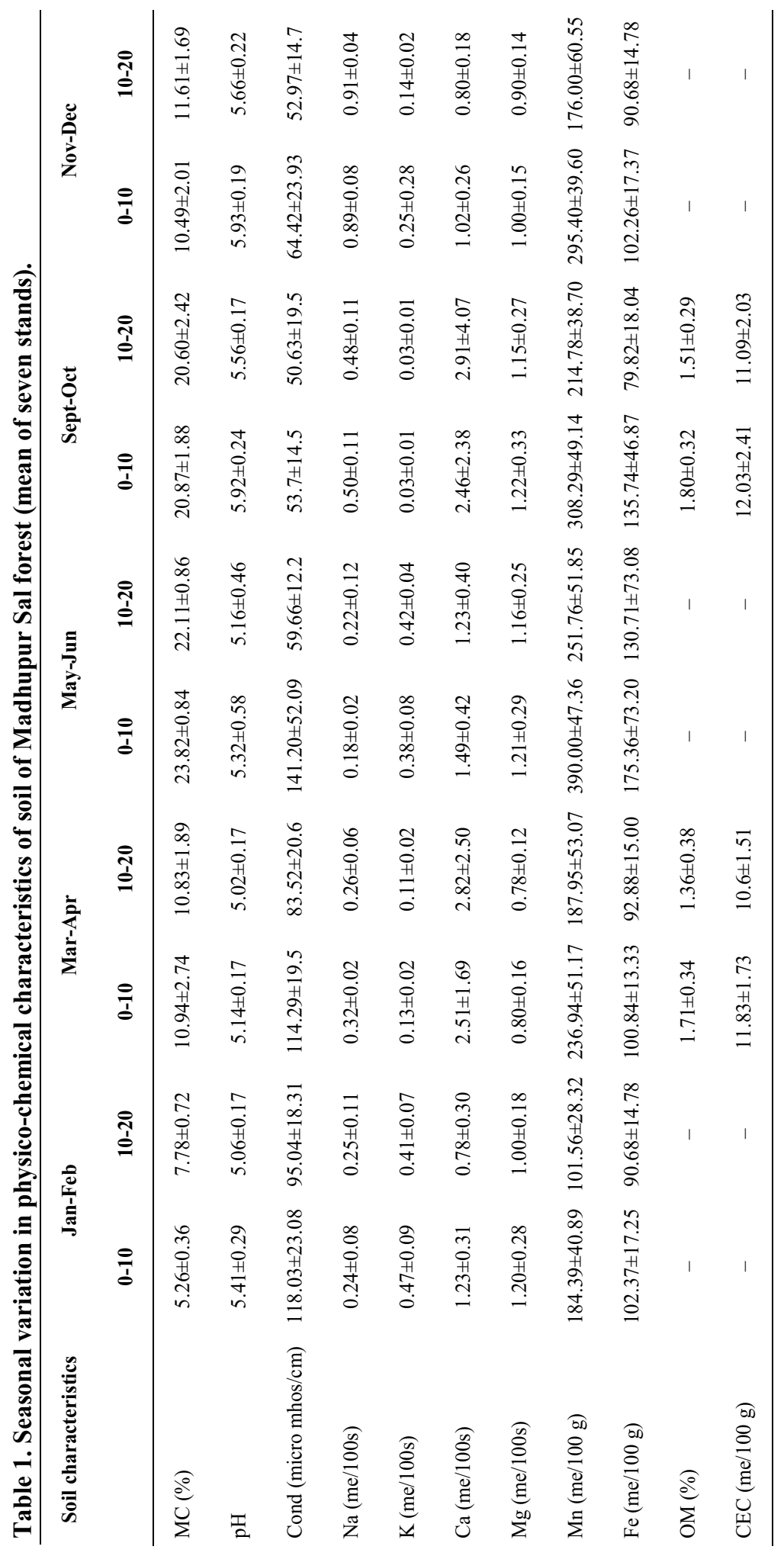


Soil organic matter and Cation exchange capacity (CEC) of soils: Organic matter content in soils of different stands is given in Table 1. The result indicates that the values varied due to seasonal fluctuation. It was a common phenomenon to all the stands condition that the percentage of organic matter content was higher in top soil layer than sub soil layer. In the months of March-April (dry season) the average mean value of organic matter was $1.71 \%$ in top soil and $1.36 \%$ in sub soil layer in March-April. In the months of September-October (wet season) the average mean value of organic matter content was $1.94 \%$ in top soil and $1.51 \%$ in sub soil layer. As a whole it is seen that the organic matter content was highest in wet season and was lowest in dry season.

The variation of CEC in soils was found to range between 7.60 to $14.00 \mathrm{me} / 100 \mathrm{~g}$. CEC was a bit higher in top soil than sub soil layer. The remarkable variation was not found in wet and dry seasons. In some stands, cation exchange capacity was the same in both top and sub soil layer. In the months of March-April, the average mean value of CEC was $11.83 \mathrm{me} / 100 \mathrm{~g}$ in top soil layer and $10.60 \mathrm{me} / 100 \mathrm{~g}$ in sub soil layer. In the months of September-October the average mean value of CEC was $12.46 \mathrm{me} / 100 \mathrm{~g}$ in top layer and 11.09 $\mathrm{me} / 100 \mathrm{~g}$ in sub soil layer. The CEC of these soils may be rated as moderate although kaolinite is the dominant clay mineral in these soils.

It has been found that bad soil aeration and inadequate moisture are chiefly responsible for unsatisfactory regeneration. Dying back is not an interesting characteristic of Sal, but is caused by bad soil-aeration and drought, the former being due to excessive accumulation of organic matter and mositure and the consequent accumulation of $\mathrm{CO}_{2}$ and possibly toxic substances.

\section{REFERENCES}

Baker, H. and A.R. Clapham. 1939. Seasonal variations in the acidity of some woodland soil. Journal of Ecology 11:114-125.

Bannister, P. 1964. The water relations of certain heath plants with reference to their ecological amplitude. 1. Introduction, germination and establishment. Journal of Ecology 52:423432 .

Coile, T.S. 1939. Distribution of forest tree roots in North Carolina in Piedmont soils. $J$. Forestry 35:247-257.

Eggeling, W.J. 1947. Observations on the ecology of the Budongo rain forest, Uganda. Journal of Ecology 34:20-87.

Gill, C.J. 1970. The flooding tolerance of woody species-A Review. Forestry Abstracts. Volume 31. No. 4. Published by the Coommonwealth Agricultural Bureaux. Famham Royal, England.

Grable, A.R. 1966. Soil aeration and plant growth. Advan. Agron. 18:37-105.

Grubb, P.J. 1963. A comparison of Montana and lowland rainforest, Equador. Journal of Ecology 51:567-601.

Gupta, P.L. and I.H. Rorison. 1974. Effects of storage on the soluble phosphorus and potassium content of some Derbyshire soils. $J$. Applied Ecology 11:1185-1192.

Hesse, P.R. 1971. A Text Book of Soil Chemical Analysis. William Clowes and Sons Ltd. London.

Leeper, G.W. 1947. Forms and reactions of manganese in the soil. Soil Sci. 63:78-94.

Lutz, H.L. and R.F. Chandler. 1955. Forest Soils. John Willey and Sons, New York. 
Nazrul-Islam, A.K.M. 1989. Effects of moisture regimes on the availability of $\mathrm{Mn}$ and $\mathrm{Fe}$ in different soil types. Geobios 17:11-16.

Nazrul-Islam, A.K.M. 1995. Ecological conditions and species diversity in the Sundarban mangrove forest, Bangladesh. In: Biology of Salt Tolerant Plants. (eds.) Khan, M.A. and I.A. Unger. Book Crafters. 6 BE Industrrial Drive. Chelsea. Michigan. USA, pp. 294-305.

Nazrul-Islam, A.K.M. and I.H. Rorison. 1978. Field investigation of seasonal oxidationreduction conditions in soil and changes in the mineral contents of shoots of associated species. Dacca University Studies 26:57-65.

Nazrul-Islam, A.K.M. and U.K. Saha. 1980. Some aspects of ecology and physiology of soyabean under waterlogged and non-waterlogged conditions. Bangladesh J. 5(12):54-59.

Ovington, J.D. and H.A.I. Madgwick. 1957. Afforestation and soil reaction. J. Soil Sci. 8:141-149.
Pearsall, W.H. 1938. The soil complex in relation to plant communities. 1. Oxidation-reduction potentials in soils. Journal of Ecology 26:180209.

Pearsall, W.H. and C.H. Mortimer. 1939. Oxidation-reduction potentials in waterlogged soils, natural water and mud. Journal of Ecology 27:483-501.

Puri, G.S. 1952. The amount of foliar ash in Sal (Shorea robusta) forests of Dehra Dun valley, U.P. India. Indian For. 76:292-309.

Rodrigo, D.M. and A.G. Pollard. 1962. The chemistry of waterlogged soil. 1. Influence of pH and organic matter. J. Sci. Fd. Agric. 3:4348.

Taylor, C.A., H.F. Blancy and W.W. McLaughlin. 1935. The wilting range in certain soils and ultimate wilting point. Trans. Amer. Geophys. Union 15:436-444.

Wilde, S.A. 1954. Reaction of soils: Facts and facilities. Ecology 35:89-99. 